\title{
Economic Factors Analysis and Optimization Strategy of Third- generation Nuclear Power
}

\author{
Zhou Fang ${ }^{1, *}$ \\ ${ }^{1}$ Shanghai Nuclear Engineering Research and Design Institute Co., Ltd., 200233 Shanghai, P.R.China
}

\begin{abstract}
Due to the project delay, the construction price of the first unit of the two types of third-generation nuclear motor type AP1000 and EPR in China is higher than the local benchmark price of coal. If the delay is not considered, only the first unit factor is considered, the price should be between $0.48-0.49$ yuan $/ \mathrm{kWh}$. Compared with the construction period and electricity price of solar power generation and wind power, this price still has no advantage. Therefore, the economic efficiency of nuclear power has become a key factor to determine whether nuclear power can occupy a place in the future power market and then get rapid development. In this paper, combined with the construction experience of third-generation nuclear power in China, a comprehensive economic analysis of nuclear power is carried outfrom the design requirements, equipment procurement, construction period, financing channels, operation and maintenance strategies and other factors, so as to provide direction guidance for the economic improvement of the subsequent batch construction of the third-generation nuclear power and the better participation of nuclear power in the power market competition.
\end{abstract}

\section{Introduction}

At present, with the economy of China turning to highquality development, the medium and long-term trading scale of electric power has been significantly improved, the power generation and consumption plan has been rapidly liberalized, and the construction of the electric power market has achieved initial results. In 2019, the medium and long-term market-oriented trading power is 2.18 trillion $\mathrm{kW} \cdot \mathrm{h}$, accounting for $30.1 \%$ of the total social power consumption [1]. Meanwhile, with the improvement of renewable energy consumption capacity, the low-carbon transformation of energy structure is steadily promoted [2]. In 2019, the utilization rate of wind power in China will reach $96 \%$, and the utilization rate of photovoltaic will reach $98 \%$ [3], all exceeding the national development and Reform Commission $88 \%$ and $95 \%$ of the clean energy consumption action plan (20182020) issued by the National Energy Administration [4]. From the overall development trend, solar power, wind power and other clean energy are developing rapidly, and occupy the traditional fossil energy market in an all-round way. For nuclear power, the Chinese government also attaches great importance to the economy of nuclear power to ensure that nuclear power can effectively participate in the increasingly open power market competition. Considering the fixed price mechanism, floating price mechanism, ladder price mechanism and market-oriented transition mechanism, it is recommended to adopt the combination of floating price mechanism and market mechanism. According to the current calculation conditions of nuclear power price, it is expected that the grid price will be about 0.43 yuan / $\mathrm{kWh}$ [5]. This indicates that nuclear power is about to face the unprecedented pressure of fully liberalized power market competition. The economy of nuclear power is reflected in the competitiveness indicators such as project cost, power generation cost and on grid electricity price. Therefore, this paper will comprehensively study the key links of the whole chain, such as the rationality of design requirements, equipment procurement mode, construction period control, financing channel expansion, operation and maintenance strategy optimization, which is of great significance to continuously reduce the cost of each main link of nuclear power, so as to improve the overall economy.

\section{Economy and Project Cost}

When it comes to the economic problem of nuclear power, it is necessary to clarify the difference between the two concepts of engineering cost and economy. Because of the mixed use of these two concepts, it will have an impact on the objective, comprehensive and complete analysis of the elements of nuclear power economy, and even reach two different conclusions in some parts.

Project cost refers to the total investment in the construction stage of the project, including design cost, equipment cost, engineering construction (including commissioning) cost and financial financing cost. The project cost is generally expressed as the budget of the project in the initial stage, and the final settlement in the

\footnotetext{
${ }^{*}$ Corresponding author: fangz@snerdi.com.cn.

This paper is supported by the National Science and Technology Major Project (2017ZX06002001)
} 
implementation stage, that is, the final completion price. The cost is divided into basic price (static investment), fixed price (static + price difference) and built price (dynamic investment). The basic price is the total investment determined by the benchmark time, that is, the total cost of nuclear power plant calculated by the price of equipment and materials, labor unit price and machine shift price of the current period. The fixed price is the total amount of construction cost which considers the floating price year by year on the basis of the base price. The completion price is the sum of the fixed price and the interest during the construction period.

Economy refers to the expenditure of cost covering the whole life cycle of nuclear power, including the construction stage, operation and maintenance stage, and the final retirement stage. Economy is the most comprehensive, complete and objective evaluation of nuclear power units, which avoids the hidden reduction of unit quality caused by over emphasis on project cost, and the additional increase of operation and maintenance costs.

\section{Analysis of Economic Elements}

The economic analysis of nuclear power plant construction stage mainly focuses on the project cost to analyze the main components of each section. Taking the construction cost of a third generation nuclear power plant as an example, the proportion of its basic price is shown in Table 1 .

Table1. Proportion of basic price of a third-generation nuclear power plant

\begin{tabular}{|c|c|c|}
\hline No. & Cost items & $\begin{array}{c}\text { Proportion } \\
(\mathbf{\%})\end{array}$ \\
\hline 1 & Preliminary engineering & 2.30 \\
\hline 2 & $\begin{array}{c}\text { Equipment of nuclear island, } \\
\text { conventional island and BOP }\end{array}$ & 50.05 \\
\hline 3 & $\begin{array}{c}\text { Installation of nuclear island, } \\
\text { conventional island and BOP }\end{array}$ & 7.60 \\
\hline 4 & $\begin{array}{c}\text { Water supply and drainage, auxiliary } \\
\text { production, living support and other } \\
\text { engineering }\end{array}$ & 4.85 \\
\hline 5 & Design & 8.30 \\
\hline 6 & Project construction management & 9.30 \\
\hline 7 & Basic reserve & 5.20 \\
\hline 8 & Fuel of first furnace & 4.80 \\
\hline & Total & 100 \\
\hline
\end{tabular}

According to the proportion of the basic composition fee in Table 1, the first one to bear the brunt is the cost of equipment. Equipment cost accounts for the highest proportion of nuclear power investment, and it is also the most critical part of the whole project construction. The main equipment related to nuclear safety, such as pressure vessel, steam generator, instrumentation and control, reactor internals, safety system equipment, etc., is the main component of equipment cost, especially the equipment that cannot be replaced or the replacement cost of subsequent power plant operation is huge Identification and other requirements are relatively high, and most of them are customized products.

The completion price of nuclear power plant has always been an issue of great concern and attention for nuclear power investors. According to table 2, the increase of the construction price mainly comes from the loan interest during the construction period. Therefore, on the one hand, the construction period has a great impact on the economy, especially in the late stage of the project construction, the delay of the construction period will produce a lot of loan interest and management costs. On the other hand, reasonable allocation of project funds can also reduce loan interest to a certain extent. The built-up price is finally recorded into the power generation cost in the form of depreciation and amortization. It can be said that the built-up price directly affects the economic benefits of nuclear power.

Table2. Proportion of construction price of a thirdgeneration nuclear power plant

\begin{tabular}{|c|c|c|}
\hline No. & Cost items & $\begin{array}{c}\text { Proportion } \\
(\mathbf{\%})\end{array}$ \\
\hline 1 & Preliminary engineering & 1.88 \\
\hline 2 & $\begin{array}{c}\text { Civil engineering of nuclear island, } \\
\text { conventional island and BOP }\end{array}$ & 6.00 \\
\hline 3 & $\begin{array}{c}\text { Equipment of nuclear island, } \\
\text { conventional island and BOP }\end{array}$ & 41.00 \\
\hline 4 & $\begin{array}{c}\text { Installation of nuclear island, } \\
\text { conventional island and BOP }\end{array}$ & 6.00 \\
\hline 5 & $\begin{array}{c}\text { Water supply and drainage, auxiliary } \\
\text { production, living support and other } \\
\text { engineering }\end{array}$ & 3.97 \\
\hline 6 & Design & 6.80 \\
\hline 7 & Project construction management & 7.62 \\
\hline 8 & Basic reserve & 4.26 \\
\hline 9 & Fuel of first furnace & 3.93 \\
\hline 10 & Reserve fund for price difference & 1.54 \\
\hline 11 & Loan interest in construction period & 17.00 \\
\hline & Total & 100 \\
\hline
\end{tabular}

(2) After the completion of nuclear power, the composition of the cost during the operation period is also an important factor affecting the economy of nuclear power. The cost during the operation period mainly includes: depreciation cost, fuel cost, material cost, salary and welfare, overhaul cost, amortization cost, retirement fund, post-processing cost, financial cost and other costs. Taking a nuclear power plant as an example, the proportion of average annual cost during its operation period is shown in Table 3.

Table3. Proportion of operating cost of a nuclear power plant

\begin{tabular}{|c|c|c|}
\hline No. & Cost items & $\begin{array}{c}\text { Proportion } \\
(\mathbf{\%})\end{array}$ \\
\hline 1 & Fuel & 14.16 \\
\hline 2 & Material & 7.70 \\
\hline 3 & Wages and benefits & 2.09 \\
\hline 4 & Depreciation & 36.82 \\
\hline 5 & Overhaul & 10.27 \\
\hline 6 & Amortization of intangible assets & 2.04 \\
\hline 7 & Retirement fund & 5.81 \\
\hline 8 & Nuclear reprocessing & 3.85 \\
\hline 9 & Financial expenses of repaying the & 13.09 \\
\hline 10 & loan & 4.17 \\
\hline & Other costs & 100 \\
\hline
\end{tabular}

It can be seen from table 3 that the fuel cost is basically fixed. For nuclear power plants, wages and benefits are implemented in strict accordance with the requirements of SASAC (State-owned Assets Supervision and administration commission) and are generally 
controllable. The reduction in this area needs to be solved by reducing the number of personnel in the power plant. Depreciation and amortization expenses are converted according to the construction price. Therefore, the control of this part of expenses is mainly realized through the cost control during the construction period. Decommissioning fund and nuclear reprocessing fee shall be drawn according to the prescribed proportion. The financial cost during the operation period is mainly the repayment cost of the loan during the construction period, which is also closely related to the construction cost during the construction period. During the operation period, on the premise of smooth operation, the economic improvement is mainly realized by effectively controlling the cost of major repair, including equipment replacement, technical transformation, etc. At the same time, the cost during the operation period is closely related to the overall construction quality during the construction period.

\section{Influence Analysis and Optimization Strategy of Economic Factors}

\subsection{Design Requirements}

In order to improve the economy of nuclear power, it is essential to make a comprehensive simplification of the safety system through the revolution of technical concept on the premise of ensuring the safety function, including reducing the number of safety system settings, simplifying the configuration of the safety system itself, and reducing the dependence of the safety system on its supporting system.

Whether the key technologies can be broken through is very important to improve the economy of nuclear power. At present, nuclear power units are designed with multiple safety barriers to prevent radioactive material leakage. In addition, a large-scale off-site emergency response was set up to deal with the release of radioactive materials. Only when the intrinsic safety of nuclear power is solved in the fundamental technical principle, can the off-site emergency be cancelled, and the nuclear power unit be established in the area close to the load center, so as to maximize the economic benefits.

The selection of design standards has a great impact on the economy of nuclear power. Therefore, we still need to speed up the establishment of a complete national standard system for nuclear power, and focus on the integration of standards. It is necessary to establish and optimize China's national standard system from the perspective of overall balance.

\subsection{Equipment Procurement}

In the fixed investment of nuclear power, the purchase cost of equipment accounts for nearly half of the total investment. Therefore, through the necessary market competition mechanism and the innovation of procurement mode, the cost of equipment procurement can be effectively reduced.
At present, the pricing mechanism of nuclear power equipment, especially the equipment with high technology and certain monopoly nature, is abnormal, and the market role is marginalized. The price is more formed in a specific period and under special projects, which does not effectively reflect the equipment manufacturing, management costs and moderate profits. For equipment supplied mainly by domestic enterprises, the technical threshold is usually lower than that of nuclear equipment, and the importance of equipment is also lower, which may be characterized by low unit price and large quantity. For this kind of equipment, we should fully tap the role of the market, form a fully competitive market environment, and truly realize the market to determine the price of equipment.

Besides introducing market mechanism, the strategy of specific equipment procurement can also be optimized to reduce the purchase price of equipment. The main way is multi project intensive and standardized procurement. In addition, the subcontracting strategy of procurement is also an important means to solve the problem that some equipment with small quantity can be supplied at a reasonable price.

Taking the procurement of equipment gate and personnel gate of a nuclear power plant in China as an example, the price of single equipment has been reduced by $30 \%$ from six equipment of two units to 24 equipment of eight units. At the same time, the implementation of "reactor types" driven equipment procurement strategy can also reduce equipment adaptive design. To reduce the uncertainty of equipment is to reduce the risk of project delay, reduce the engineering design modification on site, and provide an important premise for the final implementation of the spare parts management strategy of multi power plants based on "reactor types" . The equipment procurement strategy driven by "reactor types" can also promote the cooperation of equipment procurement among different groups, promote the formation of equipment procurement alliance, and truly control the market pricing power of equipment.

\subsection{Construction Period}

The construction period of nuclear power project is generally divided into two stages: before the first stage is the first tank concrete (FCD), it is usually called the early stage of the project. The second stage is from the first concrete tank to the commercial operation of the unit, which we call the construction period. Taking the advance fund investment of a nuclear power plant as an example, the total investment of two units in the project calculation is nearly 40 billion. The overall project cost has risen to 500 billion due to the project delay. Therefore, if the construction period is delayed, the financial cost will be further increased, which will bring heavy financial burden to the operation of nuclear motor after it is built. On the contrary, if the construction period is shortened, it can not only reduce the financial cost during the construction period, but also make the investor benefit earlier and accelerate the repayment of the loan. 


\subsection{Financing Channels}

The sources of funds for nuclear power construction include self raised funds and loans. Due to the large amount of investment, on the one hand, it is necessary to plan the capital investment plan in an orderly way. On the basis of meeting the capital required for the project construction, it is necessary to reduce the capital investment in the early stage as far as possible and reduce the financial cost. On the other hand, we should expand financing channels and obtain low interest rate loan funds as far as possible. In specific projects, it is suggested that the financing scheme and fund use plan should be taken as a special topic to carry out top-level planning and optimization, and make full use of all kinds of low-cost funds at home and abroad to support the project construction.

First of all, we need to strictly control the capital investment of nuclear power projects in the preparation period. Due to the uncertainty and long cycle of nuclear power approval, it is necessary to strictly control the capital investment in the preparation period, so as to reduce the initial cost of nuclear power project and the additional cost of waiting for approval period. Secondly, in the use of funds, the capital should be used first, and then the loan should be used. For funds with different loan interest rates from different banks or channels, low interest rate loans should be used first, and then high interest rate loans should be used. Thirdly, we should fully expand financing channels (such as issuing corporate bonds, syndicated loans, etc.) so as to make rational use of the financing function of the securities market and reduce the financing cost as much as possible. Finally, the proportion of capital of nuclear power projects should be reasonably reduced through multi-channel coordination. The requirement of setting the capital ratio is to prevent the risk of project investment and financing. For nuclear power projects, on the one hand, the role of capital as a risk response is limited. On the other hand, the return rate of capital is usually greater than the financing cost. Reducing the proportion of capital in nuclear power projects can effectively improve its economy.

\subsection{Operation and Maintenance Strategy}

As mentioned in the previous analysis, the economic improvement of operation and maintenance after the completion of the nuclear power plant is mainly in three aspects, namely, shortening the duration of refueling overhaul, reducing the number and frequency of system equipment detection and replacement, and reducing the inventory of spare parts.

First of all, the power plant is in a state of shutdown during the refueling period. The longer the duration is, the greater the loss to the power plant will be. The length of overhaul time determines the availability index of power plant. At the beginning of nuclear power unit design, the time consumed by the whole refueling and maintenance key items should be considered and evaluated, and the design optimization should be carried out at the source, so as to provide shorter overhaul and refueling operation time in essence. Through reasonable optimization of maintenance tasks, test tasks and corresponding staffing, it is ensured that there are no new factors restricting the shortening of refueling maintenance time.

Secondly, in order to ensure the reliability of the system equipment, the current practice is to carry out regular tests and preventive maintenance or replacement of the safety related system equipment. On the one hand, preventive maintenance or replacement of equipment will increase the burden of power plant operation and maintenance, especially the workload during refueling overhaul, on the other hand, it also causes a certain degree of waste. Therefore, it is necessary to improve the intelligent monitoring technology and reliability analysis technology of system equipment. By monitoring the reliability of system equipment, the number of system tests, the frequency of detection, and the number of preventive maintenance or replacement of equipment are reduced. In this way, on the basis of ensuring the reliability of the system equipment, the cost of power plant operation and maintenance can be reduced, and the economy of operation and maintenance can be improved.

Finally, the spare parts stored in the nuclear power plant are to deal with temporary and sudden failures. Once the operation of nuclear power fails, if the failure equipment can be replaced in time, the safety of nuclear power can be ensured, and unplanned power reduction or shutdown can be reduced to ensure the normal operation of the power plant.

\section{Conclusion}

This paper focuses on the analysis of nuclear power economic factors and optimization strategy, but we must always put the safety of nuclear power in the first place

" To develop nuclear power efficiently on the basis of safety is always the basic policy of nuclear power construction in China. Good economy is an inevitable requirement for nuclear power to achieve high-quality development, and it is also a necessary condition for nuclear power to survive in the power market. The practice of nuclear power for more than 30 years shows that nuclear power is not only a safe and clean energy, but also an economic energy.

Nuclear power does not generate any direct carbon dioxide emissions. Moreover, the indirect emission of nuclear power is one order of magnitude lower than the direct emission of fossil fuel power generation. Therefore, under the general trend of the world's joint response to global climate change and reduction of carbon dioxide emissions, especially after the introduction of carbon emission trading market, nuclear power will undoubtedly be able to obtain additional benefits, further enhance its economy, and then enhance its competitiveness in the power market. Nuclear power will play a more important and even irreplaceable role in reducing carbon emissions and curbing climate warming.

\section{References}

1. China Federation of electric power enterprises. Transaction information of national electric power 
market in December 2019. (2020-03-01). http://www.chinapower.com.cn/bigdatamonth/20200 122/1295791.html

2. Yang Jingwei, Zhang Ning, Wang Yi, et al. Multi energy system for renewable energy consumption: review and prospect $[\mathrm{J}]$. Power system automation, $\mathbf{4 2}$ (4): 11-24 (2018)

3. National Energy Administration. Transcript of online press conference of National Energy Administration in the first quarter of 2020 . (2020-03-01). http://www.nea.gov.cn/2021-01/30/c_ 139708580. htm

4. National Development and Reform Commission, National Energy Administration. Clean energy consumption action plan (2018-2020) https://www.ndrc.gov.cn/xxgk/zcfb/ghxwj/201812/t 20181204_960958.html

5. Research and suggestions on economic issues of China's third generation nuclear power. China Energy News, 11, July 29 (2019) 